\title{
El Túnel, Orientación de los gatos: Duas janelas para...
}

\author{
Hugo Jesus Correa Retamar
}

\begin{abstract}
Resumo: Ernesto Sábato é o escritor argentino de Abstract: Ernesto Sábato is the most representative maior representatividade da atualidade. Ex-físico, ex- Argentinian writer of the present. Ex-physicist, exmilitante do partido comunista, participante do militant of the communist party, ex-participant of the movimento surrealista e crítico do mesmo, escritor que surrealism and critic of this movement, Sábato is a problematiza a questão do homem moderno, da writer who discusses the modern man, the human condição humana. Julio Cortázar, por sua vez, também condition. Julio Cortázar, also Argentinian and argentino e contemporâneo de Sábato, é o contista que contemporary of Sábato, is the writer of short stories revolucionou o conto latino-americano e flertou assim who revolutionized the Latin-American literature and como Ernesto, com o surrealismo, ainda que nunca flirted, as Ernesto did, with the surrealism, although he tenha feito parte do movimento. Ambos os escritores has never taken part in the movement. Both writers see vêem na arte a possibilidade de ultrapassar as fronteiras in the art the possibility of exceeding the borders of do real, libertando-se das amarras da sociedade reality, free from the bounds of the materialistic materialista. Assim, através de duas obras em society. Through the comparison of the works El Túnel comparação -El Túnel e Orientación de los gatos - de and Orientación de los gatos - we analyze the role of dois escritores fascinantes analisamos o papel da arte art in the liberation and transformation of the modern como libertação e transformação do homem moderno. man.
\end{abstract}

Palavras chave: surrealismo; arte; realidade; Keywords: surrealism; art; reality; freedom; liberdade; modernidade.

modernity.

Ernesto Sábato, o último dos grandes escritores argentinos do século XX, nasce no dia 24 de junho de 1911, em Rojas, uma cidadezinha na província de Buenos Aires. Júlio Cortázar, outro argentino, nascido em 1914, em Bruxelas, falece dia 12 de fevereiro de 1984. A obra de ambos escritores, de suma importância não apenas para a literatura argentina ou hispânica como para literatura mundial, tem em comum a contradição, a insatisfação com a crua realidade que nos é apresentada diariamente. Para tanto, analiso a coincidência de duas obras dos referidos autores que, mesmo afastadas no que se refere à forma e à época, refletem pontos comuns de mediação entre o homem, a solidão, a realidade, a transcendência através da linguagem artística que nessas duas ficções pode funcionar como uma espécie de religião ${ }^{1}$

\footnotetext{
* Hugo Retamar é Licienciado em Letras (UFRGS) e mestrando da Universidade Federal do Rio Grande do Sul na área de Literaturas de Língua espanhola. Atualmente atua na área de ensino de Língua e Literaturas de Língua espanhola e é professor substituto da Universidade Federal do Rio Grande do Sul. E-mail para contato: hojarasca@ig.com.br

${ }^{1}$ Mais adiante explicitarei o conceito de arte como religião que norteia este trabalho.
} 
No romance El Túnel (1948), Juan Pablo Castel - pintor, artista governado pela razão, que odeia grupos ou seitas - é o réu confesso do assassinato de Maria Iribarne, uma jovem com quem teve um breve e obsessivo romance que lhe deixou marcas profundas. Juan Pablo conhece Maria em uma de suas exposições, enquanto esta admira um quadro seu chamado Maternidad. Maria, ao contrário dos demais expectadores (entre estes os críticos de arte), detém-se num detalhe do quadro de Castel, justamente segundo o pintor a parte mais importante da tela. Diz Castel:

En el salón de Primavera de 1946 presenté un cuadro chamado Maternidad. Era por el estilo de muchos otros anteriores: como dicen los críticos en su insoportable dialecto, era sólido, estaba bien arquitecturado. Tenía, en fin, los atributos que esos charlatanes encontraban siempre en mis telas, incluyendo "cierta cosa profundamente intelectual. (SÁBATO, 2000, p.12).

Para Juan Pablo, avesso às generalidades apontadas pelos críticos que representam a sociedade e a reificação, Maternidad seria sua obra prima. Em tal quadro, havia uma mulher em uma janela num canto perdido da tela sólida e bien arquitectada. Maria Iribarne percebe esta mulher, detém-se na janela, olha através da janela, escuta o "llamado apagado y distante" (SÁBATO, 2000, p. 12) "la soledad ansiosa y absoluta" (SÁBATO, 2000 p. 12) da mulher do quadro. Logo, Castel identifica-se como Maria por meio do quadro, já que esta transcende a obviedade fácil, isto é, atravessa o limite aparente, compreende a poesia de sua pintura.

Antes de Maternidad, Juan Pablo também fazia parte daquelas pessoas que ele mesmo criticava, pessoas que não eram capazes de ver a poesia assim como os críticos. Todos seus quadros anteriores eram medidos, pensados. Maternidad foi a única experiência na qual o pintor pôs sua alma, que aflorou após uma noite de descoberta, de sonambulismo, isto é, momento em que não há o crivo da razão, em que realidade e sonho são uma coisa só. Diz Juan Pablo a Maria Iribarne sobre a criação de sua obra prima:

- Antes los pensaba mucho, los construía como se construye una casa. Pero esa escena no: sentía que debía pintarla así, sin saber bien por qué. Y sigo sin saber. En realidad, no tiene nada que ver con el resto del cuadro y hasta creo que uno de esos idiotas me lo hizo notar. Estoy caminando a tientas, y necesito su ayuda porque sé que siente como yo. (SÁBATO, 2000, p. 42).

Castel, ao pintar Maternidad, nasce para a poesia e, ao descobrir alguém que seja capaz de vê-la e de compartilhar suas angústias, seu delírio da janela, descobre também o amor. Maria é capaz de ver a poesia, logo, também é capaz de amar. Por outro lado, o pintor estava perdido em uma sociedade materialista da qual ele também era integrante, porém sua alma tinha angústias que se manifestam através da pintura, que é motivadora e mediadora do amor; a arte é aqui principio de liberação. Após o encontro com Maria, Castel desenvolve um 
tipo de obsessão (já que ainda estava muito preso à sociedade materialista), e Maria mostra-se totalmente o oposto do pintor. Maria é imprecisa, misteriosa, livre, enigmática. Juan Pablo, ainda pintor que se move pela razão, quer possuí-la totalmente pelo medo de perdê-la. Para o pintor, Maria é o amor, a liberdade, sua possibilidade de redenção, sua possibilidade de volta a si mesmo.

Tuve este sueño: visitaba de noche una vieja casa solitaria. Era una casa en cierto modo conocida e infinitamente ansiada por mí desde la infancia, de manera que al entrar en ella me guiaban algunos recuerdos. Pero a veces me encontraba perdido en la oscuridad o tenía la impresión de enemigos escondidos que podían asaltarme por detrás o de gentes que cuchicheaban y se burlaban de mí, de mi ingenuidad. ¿Quiénes eran estas gentes y qué querían? Y sin embargo, y a pesar de todo, sentía que en esa casa renacían en mí los antiguos amores de la adolescencia, con los mismos temblores y esa sensación de suave locura, de temor y de alegría. Cuando me desperté, comprendí que la casa del sueño era María. (SÁBATO, 2000, p.62)

A revelação chega por meio de um sonho, objeto da filosofia surrealista por onde transitaram Ernesto Sábato e muitos outros escritores da época. O sonho revela a realidade para os surrealistas, ou melhor, é também parte da realidade. No entanto, após receber a revelação do amor, Juan Pablo torna-se vaidoso e egoísta, quer dizer, tudo aquilo que repudiava na humanidade. Logo, Juan Pablo - o frio - não percebia que sendo Maria a salvação, não poderia pertencer totalmente a ninguém. A poesia do quadro leva o artista ao encontro de Maria, mostra-lhe o amor, que enfim é a liberdade. A vaidade que toma conta de Castel é totalmente oposta à poesia do quadro, é justamente a perda do amor, da liberdade, é o fim da poesia.

Ahora que puedo analizar mis sentimientos com tranquilidad, pienso que hubo em mis relaciones con María y siento que, en cierto modo, estoy pagando la insensatez de haberme conformado con la parte de María que me salvó (momentáneamente) de la soledad. Ese estremecimiento de orgullo, ese deseo creciente de posesión exclusiva debían haberme revelado que iba por mal camino, aconsejado por la vanidad y la soberbia. (SÁBATO, 2000, p.112.)

Juan Pablo Castel - transformado assim pelo amor, porém não pelo amor-poesia, mas pelo amor-vaidade, amor-posse, fruto da mesma sociedade que repudia e que o torna ciumento e egoísta - mata Maria Iribarne com facadas no coração e no ventre, isto é, dois lugares extremamente simbólicos, berços da alma e da maternidade. Após o assassinato, ainda movido pelos ciúmes, vai até Allende, o marido cego de Maria e confessa a este o crime, acusando Maria de adultério. Allende, como indica seu nome - o cego que vê além daquilo que vêem os demais -, chama a Juan Pablo de "Insensato" (SÁBATO, 2000, p. 157). Em seguida, o pintor é internado em um hospício, porém jamais esquece as palavras do cego. $\mathrm{O}$ 
que poderia querer dizer o cego com aquelas palavras lançadas ao vazio? Talvez que Juan Pablo perdeu sua única possibilidade de salvação, pois assassinou a liberdade.

Em Orientación de los gatos, de Julio Cortázar, Alana e Osiris, mulher e gato, têm uma comunicação especial na qual o narrador não consegue intervir. Alana é uma mulher misteriosa, como Maria, que produz no narrador, seu marido, uma sensação de impotência, já que durante toda a narrativa este tenta decifrá-la, bem como faz Juan Pablo com Maria em El Túnel. Alana sempre olha fixamente, é escorregadia, imprevisível, livre como Maria. Em uma das tantas tentativas de possuir ou simplesmente de aproximar-se à Alana, o narrador descobre na arte o meio de dar fim a seus propósitos. Seu primeiro intento é com a música:

Hubo un tiempo en que la música me pareció el camino que me llevaría de verdad a Alana, mirándola escuchar nuestros discos de Bartok, de Duk Ellington, de Gal Costa, una transparencia paulatina me ahondaba en ella, la música la desnudaba de una manera diferente, la volvía cada vez más Alana porque Alana no podía ser solamente esa mujer que siempre me había mirado de lleno sin ocultarne nada. (CORTÁZAR, ${ }^{2}{ }^{2}$

Entretanto, é somente com a pintura que perceberá outras Alanas, a verdadeira Alana. Segundo o narrador, a pintura fazia com que Alana fosse além de si mesma, a um terreno impenetrável, ou talvez, possível apenas para Osíris, o gato.

(...) pero enfrente a un cuadro o un grabado Alana se despojaba todavía más de eso que creía ser, por un momento entraba en un mundo imaginario para sin saberlo salir de sí misma, yendo de una pintura a otra, comentándolas o callando, juego de cartas que cada nueva contemplación barajaba para aquel que sigiloso y atento, un poco atrás o llevándola del brazo, veía sucederse las reinas y los ases, los piques y los tréboles, Alana. (CORTÁZAR,)

Alana é, então, o ser que transita entre dois mundos, ou melhor, que abarca esses dois mundos, enquanto que o narrador é aquele que não consegue projetar-se ao além, ou a outra realidade, já que está demasiadamente preso à cotidianidade e à pura razão. O narrador, assim como Castel, não consegue despojar-se da carne da sociedade do homem matéria, do homem coisa. Logo, há por parte do marido um intento incontido de conter Alana, de dominá-la, de fazê-la sua, entretanto Alana são Alanas e isso torna-se impossível. Em uma de suas idas ao museu, Alana finalmente cruza para o outro lado do espelho e não mais volta ao ver a pintura de um gato em uma janela.

Una última transformación hizo de ella una lenta estatua nítidamente separada de los demás, de mí que me acercaba indeciso buscándole los ojos perdidos en la tela. Vi que el gato era idéntico a Osiris y que me miraba a lo lejos algo que el muro y la ventana no nos dejaba ver. Inmóvil en su contemplación, parecía menos inmóvil que la inmovilidad de Alana. De alguna manera sentí que el triángulo se había roto, cuando Alana volvió hacia mí la cabeza el triángulo ya no existía, ella había ido al cuadro pero no estaba de vuelta, seguía del lado del

\footnotetext{
${ }^{2}$ Textos extraídos de http://www.juansoriano.net/biografia/textos/juliocortazar.html.
} 
gato mirando más allá de la ventana donde nadie podía ver lo que ellos veían, lo que solamente Alana y Osiris veían cada vez que me miraban de frente. (CORTÁZAR,)

No fim do conto, Alana se deixa absorver pela pintura e transcende a realidade material, enquanto seu marido a perde para sempre assim como acontece com Juan Pablo Castel e Maria Iribarne.

Após esta breve resenha crítica das duas obras, vejamos as relações que podem ser estabelecidas entre ambas e seus autores, e ainda o papel que a arte cumpre em tais narrativas.

Ernesto Sábato era, antes de escritor, um físico idealista envolvido com o Partido Comunista. Doutorou-se em Física em 1938 e através da ciência foi morar em Paris, onde trabalhava para os laboratórios Curie em pesquisas sobre radiações atômicas. Lá Ernesto conheceu o grupo surrealista em ascendência na época. Com os surrealistas, começa a escrever e pela escrita abandona a ciência. Logo nessa virada em sua biografia, tem infinita importância o surrealismo e sua preocupação com o homem e com a volta do homem ao homem. O surrealismo não foi simplesmente um movimento de vanguarda, mas é ainda hoje uma filosofia de vida. Surge como reação à modernidade e, com esta, a reificação do homem, após ter contato com as teorias de Freud. Para os surrealistas a realidade não é simplesmente o que temos diante de nós; isto é, esta, a material, é a parte mais feia da realidade, assim se explica a importância do sonho para tal forma de ver o mundo.

O surrealismo apóia-se em três colunas: o amor, a liberdade e a poesia. Há uma busca desesperada da liberdade em todos os campos. Somente a liberdade, o amor e a poesia podem reverter a transformação do homem em uma engrenagem a mais da grande roda do capitalismo. Portanto, para os seguidores de tal filosofia, não pode haver um método surrealista, método é máquina, não é poesia, não é liberdade, não é amor. O próprio pintor Salvador Dali, tido como grande surrealista, foi expulso do movimento por parecer ter criado um método surrealista de pintar e com isso ter ganhado muito dinheiro e promoção pessoal, o amor-vaidade de Castel. O surrealismo diz não às rédeas sociais e aos métodos. Juan Pablo de El Túnel pinta sua obra prima após uma noite incomum, noite de liberdade profunda. Também é por outra experiência incomum, os sonhos, que descobre o verdadeiro papel que cumpria Maria em sua vida, quer dizer, sua salvação. Para os surrealistas, não há o divórcio entre real/irreal, já que tudo é real e a mais pura e bela realidade, a realidade livre é alcançada em um lugar onde não tem poder de escolha a razão. Voltando ao contexto de Sábato, Juan Pablo não consegue libertar-se das amarras da realidade aparente e encontrar a salvação não apenas de sua alma, mas da condição humana em si. 
Por sua vez, Julio Cortázar também admira o surrealismo. Mesmo que sempre tenha dito não ser surrealista na acepção de participante do movimento, considera sua visão do mundo surrealista. Explica o próprio Cortázar em um ensaio chamado Muerte de Antonin Artaud de 1948:

El Surrealismo es ante todo concepción del universo(...) Surrealista es ese hombre para quien cierta realidad existe, y su misión está en encontrarla; sobre las huellas de Rimbaud, no ve otro medio de alcanzar la suprarrealidad que la restitución, el reencuentro con la inocencia. (CORTÁZAR, 1994, p.103).

O surrealismo relaciona-se a Julio Cortázar não de forma direta, mas, como diz o próprio escritor, é um cadáver viviente que certamente o influenciou, assim como também o influenciaram a literatura fantástica de Borges e Quiroga. Segundo Jaime Alazraki, a obra de Cortázar se enquadra em uma vertente denominada neo-fantástico, isto é, uma resignificação do fantástico do século XIX enriquecida com as experiências do surrealismo, existencialismo, das vanguardas, da Primeira Guerra Mundial e da Psicanálise. Para o neofantástico, conforme Alazraki (1983), a realidade é como uma esponja e desde seus orifícios (que para as obras se pode ler janelas) pode-se vislumbrar outra realidade. Logo, enquanto o fantástico do século XIX produzia uma sensação de terror no leitor, o neo-fantástico (fantástico renovado) produziria uma sensação de perplexidade e inquietude, muito próprias da nova realidade do século XX. Portanto, é nada mais que uma tentativa de normalizar o fantástico, e não de torná-lo algo impossível e aterrorizante.

Cortázar se diz desde criança estar no limiar da realidade concreta, fato que o aproxima dos surrealistas, pois pensa que há coisas que não podem ser explicadas simplesmente com o uso da razão, há um lugar onde a constância do verdadeiro oscila, este é o limiar. Trabalhando com noção do não-absoluto, e mesmo ao negar o absoluto e aparente, mexe profundamente com a condição humana e seus temas essenciais, ou seja, a solidão, a morte, a falta de comunicação. Vários de seus contos trabalham com este lançar-se ao desconhecido, com o atravessar ao outro lado do espelho, com transgredir as regras do visível e mergulhar definitivamente no mistério. Rapidamente cito alguns contos como Axolotl, no qual há uma dupla metamorfose (homem-animal/animal-homem); Continuidad de los parques em que a ficção invade a realidade visível (leitor é sugado pela leitura); Instrucciones para John Howels quando o expectador se transforma em personagem teatral; Casa Tomada em que o invisível apodera-se de uma casa e acaba expulsando seus verdadeiros donos; Apocalipsis de Solentiname em que negativos de fotos revelam ao narrador (no caso o próprio 
Cortázar) a realidade que seus olhos não puderam ver; e finalmente Las Babas del diablo em que o personagem central acaba entrando na realidade de uma fotografia.

Desta forma, vemos que as experiências de ambos escritores comparados neste trabalho é semelhante no que diz respeito à fragmentação ou à pluralidade do real em suas maneiras de ver o mundo. Passando para a análise de alguns elementos das duas narrativas, podemos ampliar esta relação comparativa.

Em El Túnel, encontramos uma personagem capaz de cruzar os limites da realidade. Maria reconhece-se na mulher da janela, presente no quadro de Castel, e como ela espera. A mesma Maria é a tábua de salvação e o contraponto de Juan Pablo Castel, mas é assassinada a facadas por ele no berço de sua maternidade (Materindad), isto é, no ventre. Logo, em $E l$ Túnel, a pintura adentra a realidade visível e muda-a. Maria espera como a mulher do quadro (esperar lembra maternidade), talvez não um filho, mas a mudança da sociedade ou sua morte. Aqui a ficção invade a realidade. Em Orientación de los gatos, a personagem que propicia o intercâmbio entre outras realidades é Alana, que se comunica com o gato Osíris, que parece saber mais daquilo que indica sua condição de animal. Alana não morre fisicamente como Maria, porém morre para a realidade concreta, já que entra no quadro do gato que olha pela janela e passa ela também a olhar com o felino, Alana não mais volta. Vemos então que, em Cortázar, há um deslocamento inverso ao de Sábato, já que Alana é quem entra para a tela e vai além de si mesma. Assim, em Orientación, a diferença de El Túnel é a realidade que invade a ficção.

Juan Pablo é o homem real que não entende Maria e que quer possuí-la totalmente. O pintor passa por uma experiência artística libertadora, no entanto, não está desvinculado da realidade material ao ponto de libertar-se de sua mentalidade construída sobre os pilares da razão. Por não conseguir lançar-se plenamente ao mistério, Castel decide terminar com ele, decide não se salvar e mata Maria. Da mesma forma, o narrador do conto de Cortázar também manifesta seu interesse em compartilhar com Alana a liberdade, em buscar a liberdade ao escutar músicas com Alana, entretanto, sente medo e abandona seu intento. Por fim se dá conta de que jamais poderá ser como Alana ou Osíris por não os entender, por estar também ele (como Juan Pablo) demasiadamente preso à realidade concreta. Quando percebe sua impossibilidade no museu, abandona seu intuito de aproximar-se de Alana e perde-a para sempre. Em Sábato, Juan Pablo e os críticos que tanto repudia representam respectivamente a frivolidade e o egoísmo do mundo moderno. Já em Cortázar, tais sentimentos podem estar representados na própria figura do $E u$ narrador. Ambos personagens, Juan Pablo/ Narrador, buscam o amor total, mas nenhum deles busca o amor livre. Buscam o amor-controle, o amor- 
dívida, o amor-posse, e é exatamente por esta razão que ambos o perdem, já que eram incapazes de poesia.

Em Sábato, outra figura misteriosa, além de Maria, é seu marido cego, Allende. Este parece saber os segredos mais profundos da trama. Ao saber do assassinato de Maria, Allende diz a Castel a palavra "insensato". E por quê? Fazendo referência ao próprio nome do personagem, já parece estranho que um cego se chame Allende, pois em espanhol significa "além de". É então que, se reportamo-nos à simbologia, começamos a entender um pouco mais o papel do cego na trama. Já na mitologia greco-latina, os cegos eram personagens mágicos, como é o caso de Tirésias. Há neles uma sabedoria que preenche sua incapacidade de comunicação pelos olhos. Diz Manfred Lurker "Em mitos e contos de fada, a falta física da visão pode ser uma premissa para a visão interna, para a divinação” (LURKER, 1997, p. 124). Por outro lado, em Cortázar, é o gato Osíris quem se comunica de uma maneira incompreensível com Alana. Osíris, ao contrário de Allende, comunica-se pelos olhos e vê o mesmo que Alana, porém não possui o verbo de Allende, aumentando assim o poder de seus olhares enigmáticos. Se voltarmos à simbologia, Osíris era um deus egípcio relacionado aos mitos cíclicos:

Osíris e seu mito estão abertos, em especial medida, a interpretações cósmicas, por um lado sendo representado em processos naturais de nascer e perecer; por outro, inseridos como deus do mundo subterrâneo e sol noturno na cosmologia do culto ao sol. (LURKER, 1997, p. 504).

Além disso, o gato, para os egípcios, era um animal sagrado por ser inimigo das serpentes. Nas concepções surgidas a partir do século V, passa a ser visto como um animal noturno em contexto lunar e um símbolo do feminino, tanto pelas deusas mães que os tinham como animais de estimação, como pelas bruxas que os tinham por cúmplices (Lurker, 1997, p. 284). Logo, Osíris é um ser misterioso que tem como Allende a chave dos mistérios e que não se comunica com a realidade objetiva. Concluindo, os triângulos que se formam nas duas narrativas são semelhantes e ambos se rompem:

\section{María/ Alana + Allende/ Osiris $\neq$ Juan Pablo/ Narrador $=$ Impossibilidade}

Comparando ainda as referidas obras, poderíamos salientar o nome atribuído aos personagens femininos. Em Sábato, temos Maria como Mãe (Maternidad, Maria mãe de Cristo) afeto, poesia e proteção. Em Cortázar, temos Alana que pode derivar-se do espanhol alas (asas do português), o que aponta para comunicação, já que deuses como Mercúrio, mensageiro de Zeus, tinham asas nos pés, bem como o mensageiro de Deus, o arcanjo 
Gabriel. Há então neste nome uma associação com a divindade ou uma origem celestial. No Egito, as asas eram símbolo de proteção. Para Lurker, podem representar ainda as forças da transitoriedade entre o demoníaco e o divino, já que muitas divindades que representavam tais oposições eram aladas (Fortuna, Crono, Morte, Diabo). Uma última relação apontada por Lurker e talvez a mais importante seja a que relaciona as asas à alma e ao amor que supera quaisquer distâncias. Assim, Alana e Maria provam uma vez mais serem pontes para a salvação de Juan Pablo e do narrador do conto de Cortázar já que ambas são mensageiras do amor, da liberdade e da poesia. No entanto, aqueles que deveriam ser salvos abandonam-nas, renunciando ao seu convite e renunciando, portanto a si mesmos.

Após este percurso pelas obras, qual seria a função que ocupa a arte na problemática dos dois relatos? Tomo para esta análise o conceito de arte como religião, mencionado ao iniciar este trabalho. Quando digo religião não me refiro ao que a palavra recorda-nos hoje em dia, isto é, instituição religiosa. Refiro-me sim ao sentido primeiro do termo latino Religo (FARIA, 1962, p. 856), que significava ligar. Ou seja, a arte seria assim a possibilidade de religar o homem ao desconhecido, ao além dos horizontes, a Deus, a quem for, levando-o de qualquer maneira para além de si mesmo, como o que acontece com Maria e Alana nas obras analisadas. Por outro lado, mencionamos que, em El Túnel, Juan Pablo é um artista movido pela razão. Se a função da arte é fazer com que nos libertemos, como isso é possível? Como é possível um artista movido pela razão, pelo método?

Juan Pablo, ainda que pintor, se levarmos em conta o conceito de arte mencionado, não era um artista e apenas conseguiu sê-lo em uma experiência na qual esteve realmente livre, porém como já dito renunciou a esta experiência pelo egoísmo. Em Orientación de los gatos, a arte está representada pela música, pela dedicatória do conto ao pintor mexicano Juan Soriano, e principalmente pela pintura. Por que principalmente pela pintura? E que arte seria mais própria para fazer o jogo entre duas realidades que a pintura? Em épocas anteriores, era a representação da realidade mesma, e os reis tinham seus pintores palacianos especiais, encarregados de retratá-los para a eternidade. Com as tecnologias do mundo moderno como a fotografia, a pintura passa a ocupar um plano que tem aberta a possibilidade de mergulhar em outras realidades, já que sua função primordial não era mais a de representar a realidade concreta fielmente como esta era vista pelos olhos. Assim, a pintura ocupa nas duas narrativas do Século XX uma função transformadora e libertadora do homem moderno e atormentado por essa modernidade veloz que o faz perder cada vez mais o espaço para a poesia, o espaço para encontrar-se consigo mesmo, já que vivemos no reino das máquinas. Quem pode alterar e restituir o homem ao homem? A arte, a arte como religião e o homem como deus. Segundo 
Jacobo Kogan, a Religião como a conhecemos, isto é, a crença religiosa "es el elemento de la fe previo a toda producción humana, mientras que el arte es inconcebible sin la creatividad del hombre" (KOGAN, 1987, p. 28). Logo, a arte depende do homem e é a única possibilidade de tornar o homem a ele mesmo, livre das amarras e parafusos que lhe impõe o progresso. Diz ainda Kogan:

Sin embargo, podemos concluir que lo trascendente, aquello que el hombre confusa, a veces dolorosamente, a veces com gozo intenso, vislumbra más allá de su vida de criatura singular e que fulgura con no menos resplandor en la religión y en la pureza del alma ético social, se manifiesta también en lo que podríamos llamar la religión del arte. (KOGAN, 1987, p. 243).

O romance de Sábato denuncia a crise da cultura ocidental como uma maneira para que as pessoas se levantem de seu estado apático e desesperador. Seu Juan Pablo é apenas um dos tantos homens e mulheres perdidos no abismo egoísta e cruel ao qual nos condena a vida moderna de uma sociedade quadrada e cheia de ângulos, na qual cada um é uma engrenagem a mais que faz girar a grande roda do capitalismo. Maria, ao contrário de Juan Pablo, sabe o que é o amor, vê a poesia, isto é, parece que não estamos totalmente perdidos, há ainda uma oportunidade de salvação e precisamos, precisa toda a humanidade aproveitá-la. Juan Pablo não consegue liberar-se totalmente de sua personalidade-engrenagem e não vive o amorpoesia e sim o amor-vaidade. Contudo, nós, ainda que muito parecidos, podemos ser diferentes de Castel, porque já sabemos o fim que teve o pintor por seu egoísmo e vaidade.

Em Orientación de los gatos, Alana é o símbolo da transição entre as muitas realidades, e esta transição só é possível se não estamos presos à realidade absoluta. $\mathrm{O}$ narrador não quer acompanhá-la, não porque não a entenda como diz, mas porque tem medo desta outra realidade. Alana voa e sempre olha fixamente com seu raio azul, já o narrador tem medo do olhar fixo de Alana e, como uma engrenagem a mais do sistema, segue apenas o palpável e renuncia também, como Juan Pablo Castel, à possibilidade de encontrar-se e de voar com Alana até o desconhecido. Assim, em ambos relatos, encontramos o medo e a mesquinhez de um lado, a pureza e a liberdade de outro e, entre eles, o espelho, a ponte, isto é, a arte.

Faltaria um último paralelismo entre as obras ainda não mencionado, talvez um dos mais importantes. Nas duas telas encontramos uma janela que representa o ponto de passagem, o duplo, ou melhor, de um lado vemos o outro lado, de uma realidade podemos vislumbrar outra, e esta outra realidade existe. A mulher espera em uma janela do quadro Maternidad, o gato do quadro de Orientación olha para o vazio. Não sabemos o que os espera, nos espera, do outro lado das janelas, mas devemos atrever-nos a elas para 
resgatarmos a nós mesmos. A janela é a transição entre o terreno e o transcendental e está, em ambos relatos analisados, à espera de que a cruzem, quer dizer, de que a cruzemos.

\section{Referências}

ALAZRAKI, Jaime. En busca del unicornio: los cuentos de Julio Cortázar (elementos para una poética de lo neofantástico). Madri: Gredos, 1983.

CORTÁZAR, Julio. Bestiario. Madri: Alfaguara, 1993.

. Las Armas Secretas. Madri: Cátedra, 1986.

. Obra Crítica. Madri, Alfaguara, 1994, Vol. I.

.[s.d.] Orientación de los gatos. Disponível em: http://www.juansoriano.net/biografia/textos/juliocortazar.html. Acesso em 24/05/2007.

CURUCHET, Juan Carlos. Julio Cortázar o La Crítica de la razón pragmática. Madri: Editora Nacional, 1972.

CRISTALDO, Janer. Mensageiro das Fúrias: Uma Leitura Camusiana de Ernesto Sábato. Florianópolis: Editora UFSC, 1983.

DÓNOAN. La novela como indagación de la Condición humana. In: SÁBATO, Ernesto. Sábato: Premio de Literatura en Lengua Castellana Miguel de Cervantes. Barcelona: Anthropos, 1988, p. 7-22.

FARIA, Ernesto (org.). Dicionário Escolar Latino-Português. 3 ed. Rio de Janeiro: Ministério da Educação e Cultura, 1962.

GÁLVEZ, Marina Acero. Sobre abandonos y fidelidades. In: SÁBATO, Ernesto. Premio de Literatura en Lengua Castellana Miguel de Cervantes. Barcelona: Anthropos, 1988, p. 23-54.

KOGAN, Jacobo. La Religión del Arte. Buenos Aires: Emecé, 1987.

LIBERMAN, Arnaldo; LIBERMAN, Mónica; MARÍN, Luis García. Conversación con Ernesto Sábato. In: SÁBATO, Ernesto. Sábato: Premio de Literatura en Lengua Castellana Miguel de Cervantes. Barcelona: Anthropos, 1988, p. 63-76.

LURKER, Manfred. Dicionário de Simbologia. São Paulo: Martins Fontes, 1997.

PONGE, Robert (org.). O Surrealismo (Literatura, Artes Plásticas, Teatro, Cinema, Arquitetura, Filosofia). Porto Alegre: Editora da Universidade/UFRGS, 1991.

SÁBATO, Ernesto.[s.d] Disponível em: http://www.literatura.org/sabato/sabato.html. Acesso 24/01/1995. 
. El Túnel. Espanha: Planeta, 2000

Hombres y engranajes. Buenos Aires: Emecé, 1990.

. Uno y el Universo. 3. ed. Buenos Aires: Sudamericana, 1952.

VINOGUR DE TIRRI, Sara; TIRRI, Néstor (org.). La Vuelta a Cortázar en nueve ensayos. Buenos Aires: Carlos Pérez Editor, 1968. 